\title{
Influence of Vertebral Bone Marrow Edema on Outcome in Non-Acute Osteoporotic Patients Treated with Percutaneous Vertebroplasty
}

\author{
Hossam Abdelhakim Elnoamany \\ Neurosurgical Department, Faculty of Medicine, Menoufia University Hospital, Menoufia, Egypt
}

\section{Study Design: Prospective cohort study.}

Purpose: To prospectively investigate the influence of presence of bone marrow edema (BME) in non acute osteoporotic verterbral compression fractures on postoperative clinical outcome in patients treated by percutaneous vertebroplasty (PV).

Overview of Literature: Although PV is widely used to treat osteoporotic collapsed vertebral compression fractures (VCF); little is known about the influence of BME in osteoporotic VCF or about its relation with relief of pain.

Methods: Sixty seven patients with non acute osteoporotic verterbral compression fractures treated with PV. They were divided into edema group (56 patients with apparent vertebral BME in their magnetic resonance [MR] images), and non edema group (11 patients with no vertebral BME detected in their MR images). Pain was evaluated one week, one month, six months, and one year post procedure using visual analogue scale. Statistical analysis including a 2-tailed $t$ test comparing postoperative data with preoperative values was done.

Results: A good clinical response to PV procedure was seen in all patients. Significant difference was seen between two groups in one week, and one month follow up periods. Regarding pain relief in the other periods of follow up, no significant difference was seen between two groups.

Conclusions: PV resulted in significantly clinical improvement in patients with BME pattern than in those without in one week and one month follow up periods. But the absence of vertebral BME did not influence pain relief in patients with osteoporotic VCFs in six months, and one year post procedure.

Keywords: Non acute spinal fractures; Osteoporotic vertebral fractures; Bone marrow edema; Percutaneous vertebroplasty

\section{Introduction}

Many clinical entities can cause painful vertebral collapse. These include osteoporosis, vertebral hemangiomas, multiple myeloma and metastatic diseases. Of these, the most common is osteoporosis. Percutaneous vertebroplasty
$(\mathrm{PV})$ is widely accepted as a useful treatment for back pain resulting from osteoporotic compression fractures [1-7].

Magnetic resonance imaging (MRI) provides information on anatomy of vertebral collapse and the loss of signal intensity from the vertebral bone marrow space. Loss

\footnotetext{
Received Sep 1, 2015; Revised Oct 2, 2015; Accepted Oct 4, 2015

Corresponding author: Hossam Abdelhakim Elnoamany

Neurosurgical Department, Faculty of medicine, University Hospital, Menoufia University,

64, Gamal Abdel Naser Street, Shebin El Kawm, Menoufia, Egypt

Tel: +2-010-0295305, Fax: +2-048-2233771, E-mail: Hae1967@gmail.com

*This paper was presented at the 10th Asian Congress of Neurological Surgeons on Sep 9-12, 2014 in Astana, Kazakhstan.
} 
of normal signal intensity, which indicates the presence of bone marrow edema (BME), is useful in determining the vertebra that is to be treated [7-9]. However, to the best of my knowledge few studies in literature have examined the relationship between the pain relief and the presence of BME either too early postoperative (1-3 days) or starting after one month and followed up the patients for one year postprocedure $[10,11]$. So that, the purpose of this study is to prospectively investigate the influence of presence of $\mathrm{BME}$ in non acute osteoporotic verterbral compression fractures on postoperative clinical outcome in patients treated by PV.

\section{Materials and Methods}

This study which was approved by Institutional Review Board of Menoufia University, was performed between September 2011 and August 2013. All patients provided written informed consent. Inclusion criteria for vertebral compression fracture (VCF) to be treated by PV were: (1) VCF with height loss $\leq 40 \%$ of the vertebral body compared with the posterior wall height, (2) localized back pain refractive to medical therapy for at least six weeks (3) bone attenuation T-scores $<-2.0$, and (4) Patient is free of any underlying disease.

A total of Sixty seven patients with 102 non acute osteoporotic VCFs were included and treated in this study. They were divided into edema group (56 patients with apparent vertebral BME in their MR images), and non edema group (11 patients with no vertebral BME detected in their MR images). All patients were treated with PV. Age of the patients ranged from 49.7-71.3 years with mean age 61.4 years. Fifty eight were women and nine were men.

\section{MRI protocol}

MRI examinations were performed using a $1.5 \mathrm{~T}$ magnetic resonance machine. T1-weighted and fat suppressed T2weighted MRI scans were obtained in the sagittal plane. A series of images were obtained using a quadrature thoracolumbar spine coil. The imaging sequences was either sagittal T1-weighted spin-echo sequence or a sagittal T2weighted spin-echo sequence.

Vertebral bodies were classified into three subgroups according to the proportion of the vertebral body affected by BME pattern, as seen in the sagittal plane. All sagittal
MRI scans that depicted the vertebral bodies were analyzed, and three images that showed the right side, center, and left side of the vertebral bodies were selected. If the distribution of BME pattern differed on the sagittal MR images, the image with the broadest distribution was used for classification purposes. Classification criteria consisted of three types. In edema group type 1, BME pattern was present in $\geq 50 \%$ of the vertebral bodies (at least one patient have $>50 \% \mathrm{BME}$ in one vertebrae). Type 2, the BME pattern was evident in $<50 \%$ of the vertebral bodies (at least one patient have $<50 \% \mathrm{BME}$ in one vertebrae). In non edema group type 3 , the vertebral bodies did not display a pattern of BME.

\section{Procedure}

PV was performed either under local anesthesia or general anesthesia under $\mathrm{C}$-arm guidance. The bilateral transpedicular approach was used whenever the offending vertebral fracture affects the vertebrae both in right and left sides more or less equally. The unilateral transpedicular approach was performed if the vertebrae affected by a compression fracture were predominantly on one side. Acrylic resin bone cement was injected manually under continuous fluoroscopy by using $1.0 \mathrm{~mL}$ syringes and 11-gauge bone biopsy needles (Tsunami Medical, Mirandola [MO], Italy). Acrylic resin used: Exolent spine (Elmdown, Italy). The following morning, a CT scan of the treated levels was made to assess cement deposition and to identify possible extra cement leakage or other local complications that might not have been noted under fluoroscopy.

\section{Outcome evaluation}

Pain was evaluated two hours, one week, one month, six months, and one year post procedure using a visual analogue scale (VAS). Medication usage was also evaluated.

\section{Statistical analysis}

Patient and imaging characteristics were evaluated in the total study groups and subgroups. A statistical analysis including a 2-tailed $t$ test comparing postoperative data with preoperative values were done. Differences between characteristics in the subgroups were tested with chi-square $\chi^{2}$ (categorical variables) or unpaired $t$ test (continuous 
variables). The paired $t$ test was used to compare changes in VAS and the Wilcoxon paired sample test to compare type of analgesics used before and after PV.

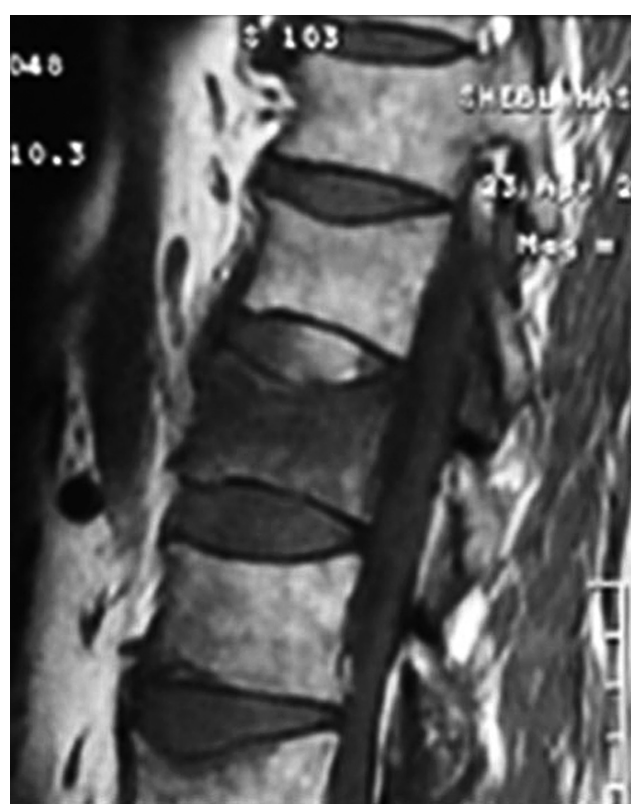

Fig. 1. T1 weighted magnetic resonance sagittal image of a patient with edema group type 1 (bone marrow edema more than $50 \%$ ).

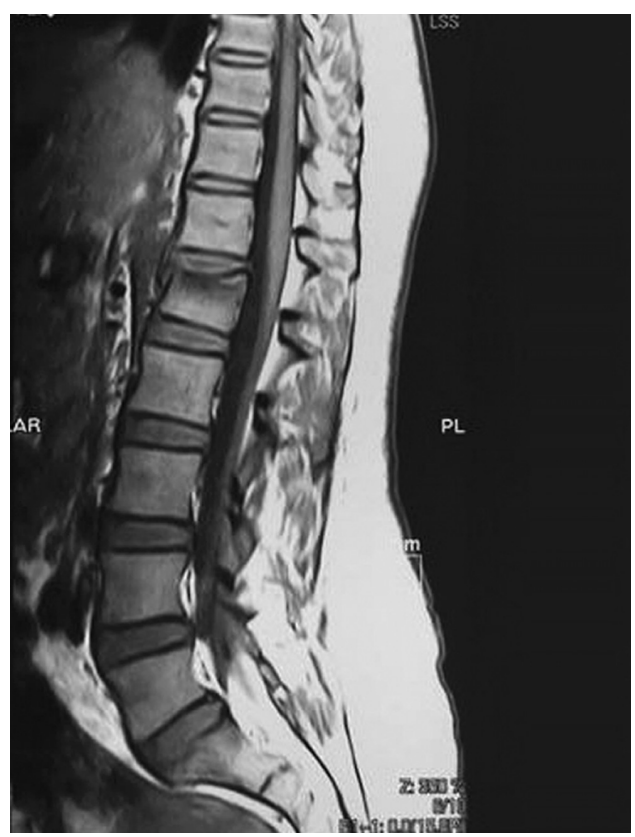

Fig. 2. T1 weighted magnetic resonance sagittal image of a patient with osteoporotic vertebral compression fracture of $L 1$, edema group type 2 (bone marrow edema less than $50 \%$ ).

\section{Results}

Forty one vertebrae were classified as type 1, 34 as type 2, and 27 as type 3 . Twenty nine patients were accordingly assigned to edema group type 1 (Fig. 1), 27 were assigned to edema group type 2 (Fig. 2), and 11 were assigned to no edema group type 3 (Fig. 3).

Postprocedural VAS and type of analgesic used was significantly lower at all intervals of follow up compared with initial values $(p<0.001)$ (Figs. 4, 5). Both VAS and type of analgesic used decreased foremost in the first week to one month after PV. Values remained fairly constant at further follow-up intervals.

A statistically significant difference was evident between edema group types 1 and 2 compared to non edema group type 3 with respect to postprocedural VAS score $(p<0.031)$ at 1 week and 1 month follow up times, and significant differences were seen between preprocedural and postprocedural VAS scores in all three groups $(p<0.001$ in edema group type $1, p<0.002$ in edema group type 2 , and

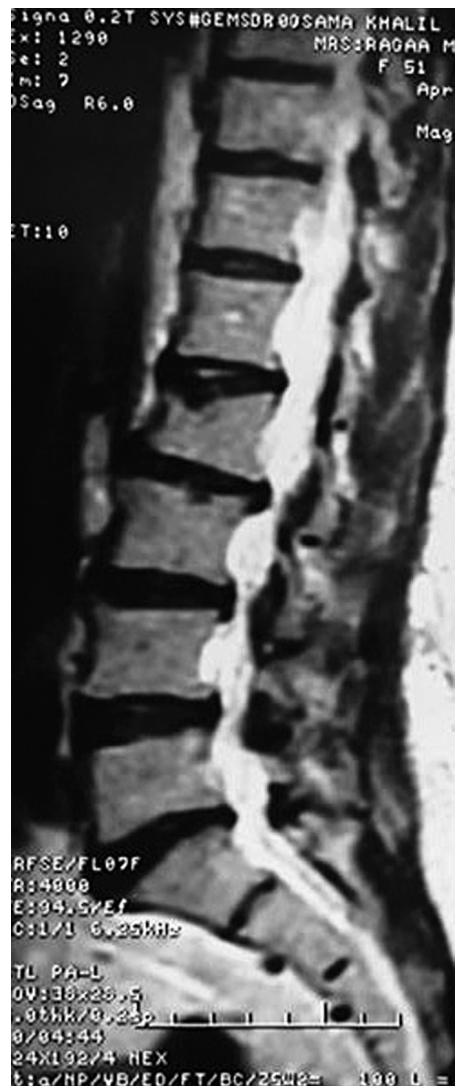

Fig. 3. T2 weighted magnetic resonance sagittal image of a patient with osteoporotic vertebral compression fracture of $L 2$, non edema group type 3 (no bone marrow edema). 


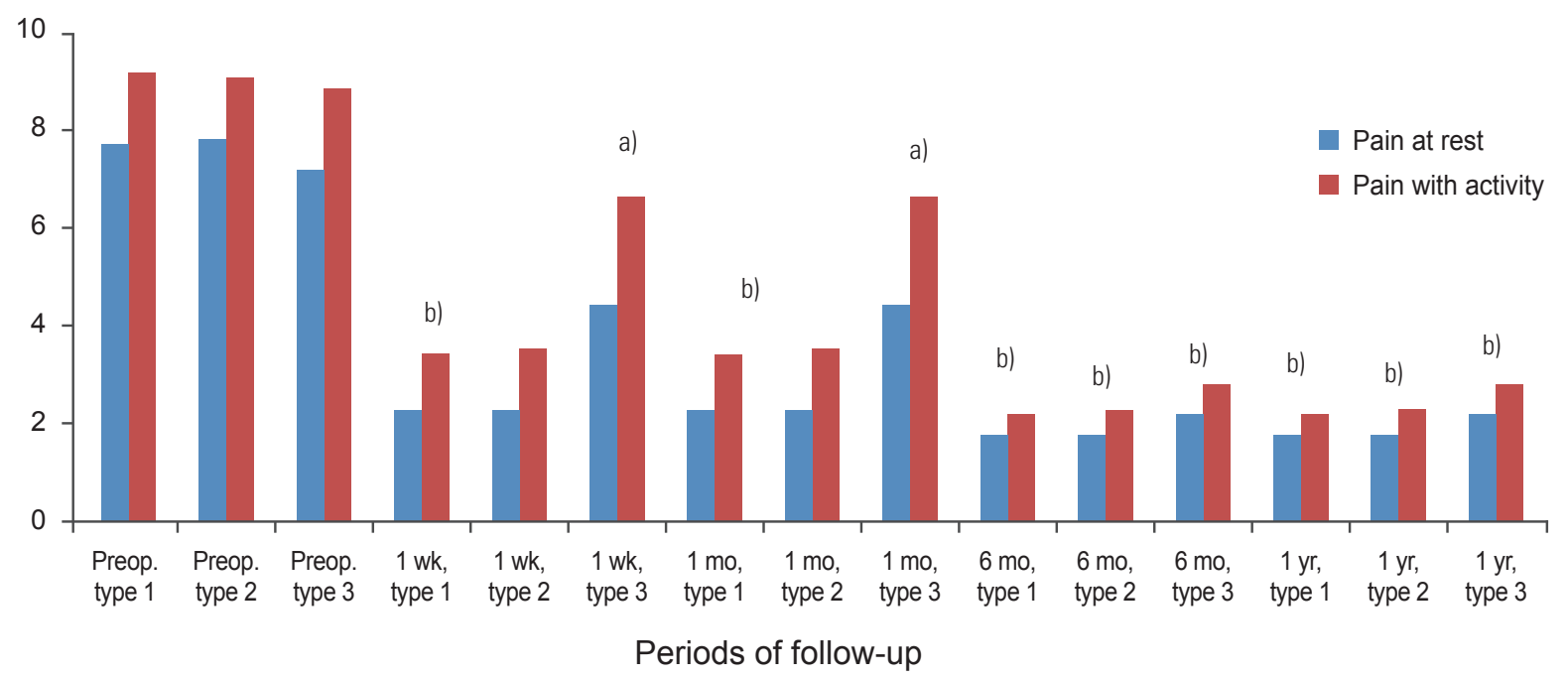

Fig. 4. Graph showing pain at rest and during activity preoperatively and following percutaneous vertebroplasty in all three subgroups at

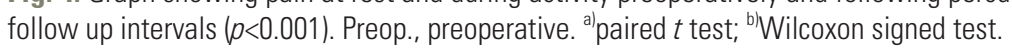

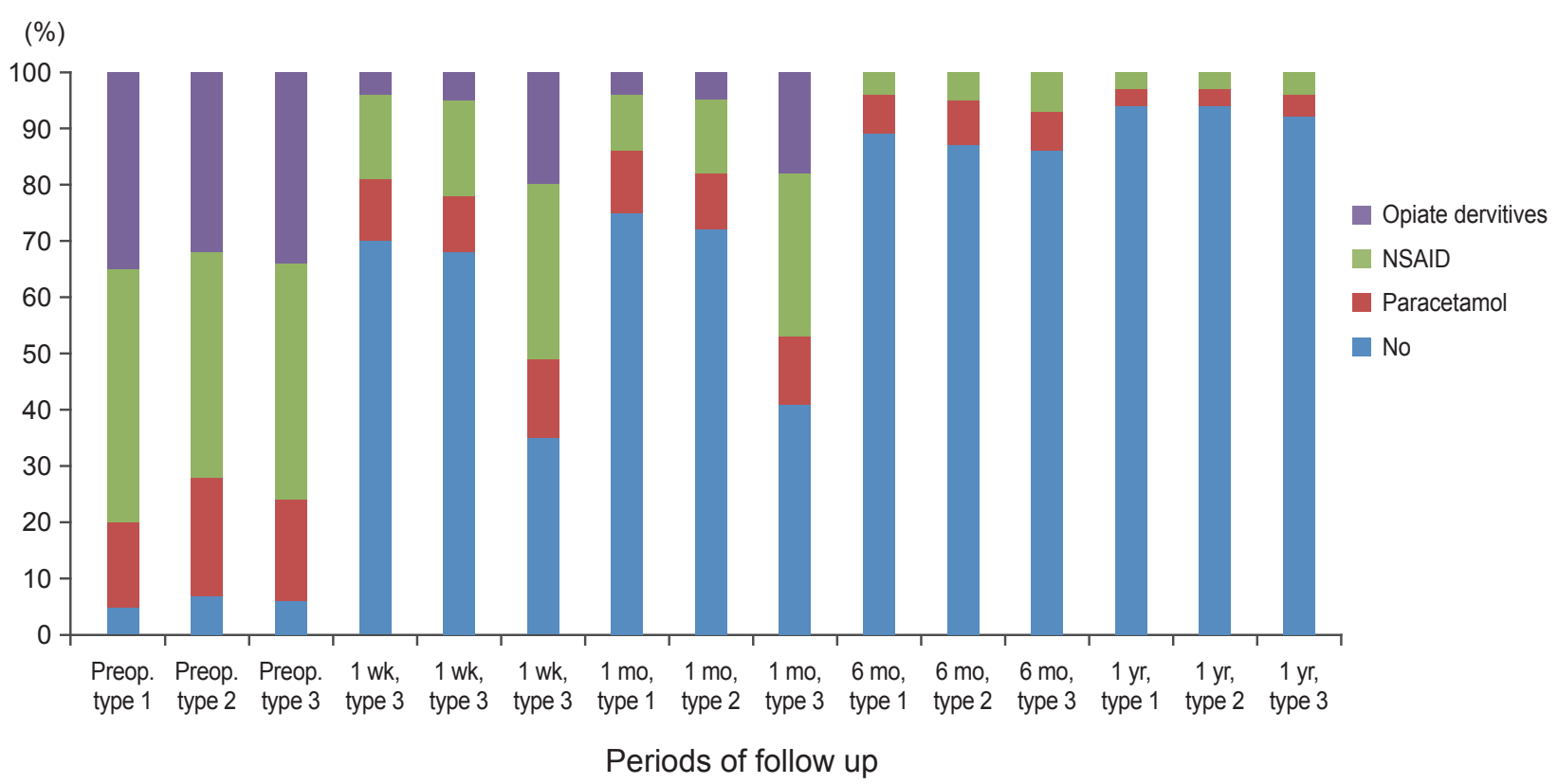

Fig. 5. Graph showing percentage of medication usage before and after percutaneous vertebroplasty in all three subgroups at follow up intervals $(p<0.001)$ (Wilcoxon paired sample test). NSAID, nonsteroidal anti-inflammatory drugs; Preop., preoperative.

$p<0.05$ in non edema group type 3 ) at the one year follow up period.

At the one month follow up period, pain reduction of at least $60 \%$ during activity was achieved in $21(72.4 \%)$ of 29 patients in edema group type 1,19 of 27 patients $(70.3 \%)$ in edema group type 2 , and sex (54.5\%) of 11 patients in non edema group type 3 . There were statistically significant differences in both pain at rest and pain with activity in all three groups at the one-week follow up period and these differences continued throughout the follow up. Patient's mobility improved significantly at post-procedure one- week, and there significant difference were evident between the edema groups (type 1 and 2) and the non edema group (type 3 ) at the one-week and one month follow up $(p<0.002)$. No significant differences between any groups were evident at six-month and one-year follow up (Fig. 6). 


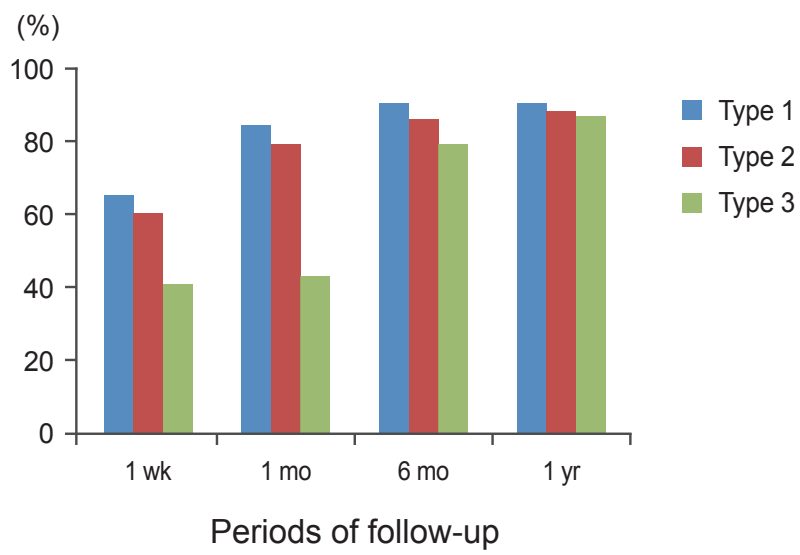

Fig. 6. Graph showing percentage of improvement in mobility following percutaneous vertebroplasty in all three subgroups at follow up intervals $(p<0.002)$ (chi-square test).

\section{Discussion}

PV is widely used to treat osteoporotic collapsed or weakened VCFs that cause moderate to severe pain and which are unresponsive to conservative therapy. Till now, little is known about the influence of BME in osteoporotic VCF and its relation with relief of pain.

In general, fractures less than one month old are hypointense on T1-weighted images and hyperintense on T2weighted and STIR sequences [12]. Approximately 1 to 3 months after vertebral collapse, most osteoporotic VCFs becomes isointense to normal bone marrow on T1- and T2-weighted sequences [13]. Fully healed VCFs demonstrate either return to normal marrow signal intensity or, in the presence of sclerosis, may appear hypointense on T1and T2-weighted sequences. Based on these observations, VCFs with BME are considered subacute and are candidates for PV with favorable response to pain $[6,7,14]$. On the other hand, VCFs without BME are considered chronic or healed and therefore not good candidates for PV.

From the clinical point of view, it does matter whether the presence of BME in osteoporotic VCFs affect the clinical outcome after VP or not. To answer this question this study was designed which included sixty seven patients with a 102 non acute VCFs (subacute and chronic VCFs).

Voormolen et al. [15] treated 45 patients with VCFs. 31 patients had full BME in their fractures and 14 patients had no BME in their fractures and followed them for 3 months. They found a favorable response on pain in VCFs treated with PV in $94 \%-97 \%$ of patients with full BME and in $71 \%$ of patients with absent BME. Relief of back pain in general after PV treatment was comparable in patients with full and absent BME [15].

To the best of my knowledge, this study is the first to asses both pain at rest and with activity and their relation to the presence or absence of BME in non acute osteoporotic VCFs. Pain scores at rest and with activity were highly significantly decreased one week postprocedural and continued for a month compared with pain scores preprocedural in both edema groups type 1 and 2 and significantly decreased in non edema group type 3 . But at six months follow up, the edema groups (type 1 and type 2 ) and non edema group (type 3 ) groups showed highly significant differences compared to preoperative pain scores either at rest or with activity. After an interval of six months follow up; there were no statistically significant differences regarding both pain at rest and pain with activity between the two edema groups (type 1 and type 2 ) and non edema group (type 3) with the lack of significance continuing through the one-year follow up interval.

The results from literature indicate that presence of $\mathrm{BME}$ in VCFs is a strong predictor of favorable response on pain relief after PV and PV in patients with absent BME should not be withheld based on the absence of BME alone. Pain response after PV can be independent of other patient or imaging characteristics $[15,16]$. In contradiction to these finding, this study included 23 patients admitted to perform PV procedure after being fractured by more than 7 months and 17 of them had BME in their MR imaging studies. That is why the presence of BME is irrelevant to the pain relief in the current patients. The current results are confirmed in studies by using bone scintigraphy, in which increased uptake in up to $41 \%$ of untreated VCFs persists for as long as 1 year after initial fracture $[17,18]$.

In another study, Voormolen et al. [11] studied the evolution of BME in vertebral bodies and its relation with relief of pain in 89 vertebrae with osteoporotic VCFs all having BME and followed them for a year and at the end of their research they concluded that; there is no relation between the presence of BME and the relief of pain post $\mathrm{PV}$ (changes in BME extent on 1 year MR imaging follow-up were unrelated to changes in pain after PV at all follow up intervals). Finally, their study indicates that; MRI follow-up after PV is generally not necessary. Plain radiographic films of the spine give information on further collapse of the treated VCF and occurrence of new VCF. Follow-up MRI is only indicated in patients with 
new symptomatic VCF in which PV is considered or in patients with unexplained residual pain.

The information from the current study denotes that; the relatively rapid relief of pain seen after PV may be due to intervertebral fixation and lack of movement of fracture fragments with PV. However, relief of pain and fracture healing seems to be two separate aspects of VCF recovery.

The early results of current study on 102 VCFs suggest that; the more extensive the BME pattern in the treated vertebra, the greater the pain relief provided by PV will be. However, no significant difference was seen between patients with a bone marrow pattern that occupied $\geq 50 \%$ of the vertebra and those in whom it occupied $>50 \%$ at one-week and one-month follow up intervals. Later results at six months and one year follow up periods showed significant reduction in pain scores in the all groups compared to the preprocedural pain levels and insignificant results between the edema and non edema groups regarding pain relief. These results are in accordance with previous reports that indicated that while PV is effective in treating chronic compression fractures, it is more effective in treating acute compression fractures [14].

This is the only report to discuss the percentage of improvement in postprocedural mobility and its relationship to the presence or absence of BME which is the land mark to regain the normal daily activities. The results of this report showed significant improvement in mobility of the patients as early in follow up time and the improvement continued throughout the whole time of follow up. At early follow up periods (one week and one month); there were significant differences between edema groups (type 1 and type 2) and non edema group, but after six months follow up interval; no significant differences had been recorded between the three types.

The use of opiate derivatives was significantly decreased post PV in all types at one week follow up period and continued to one month interval. There was a significant difference between the edema groups (types 1 and type 2) and non edema group type 3 at one week and one month follow up times. In later follow up periods (six months and one year), the difference between the all groups was insignificant. Most of the treated patients stopped opiate derivatives after a month postoperatively and used either Paracetamol or non-streroidal anti-inflammatory drugs to control residual pain. These results are in accordance with the previous reports in literature [11,15,19-25].

\section{Conclusions}

$\mathrm{PV}$ resulted in significantly clinical improvement in patients with BME pattern than in those without BME in early follow up periods. But the absence of BME did not influence pain relief and improvement in mobility in patients with osteoporotic vertebral compression fractures at the six months, and one year post procedure follow up periods. Thus, either the presence or absence of BME in treated osteoporotic VCFs is unrelated to improvement in clinical outcome. So, the results of this study recommend that, PV should not be withheld based on absence of BME alone.

\section{Conflict of Interest}

No potential conflict of interest relevant to this article was reported.

\section{References}

1. Evans AJ, Jensen ME, Kip KE, et al. Vertebral compression fractures: pain reduction and improvement in functional mobility after percutaneous polymethylmethacrylate vertebroplasty retrospective report of 245 cases. Radiology 2003;226:366-72.

2. Heini PF, Walchli B, Berlemann U. Percutaneous transpedicular vertebroplasty with PMMA: operative technique and early results: a prospective study for the treatment of osteoporotic compression fractures. Eur Spine J 2000;9:445-50.

3. Hodler J, Peck D, Gilula LA. Midterm outcome after vertebroplasty: predictive value of technical and patient-related factors. Radiology 2003;227:662-8.

4. Kallmes DF, Comstock BA, Heagerty PJ, et al. A randomized trial of vertebroplasty for osteoporotic spinal fractures. N Engl J Med 2009;361:569-79.

5. Klazen CA, Lohle PN, de Vries J, et al. Vertebroplasty versus conservative treatment in acute osteoporotic vertebral compression fractures (Vertos II): an openlabel randomised trial. Lancet 2010;376:1085-92.

6. Kallmes DF, Jensen ME. Percutaneous vertebroplasty. Radiology 2003;229:27-36.

7. Mathis JM, Barr JD, Belkoff SM, Barr MS, Jensen ME, Deramond H. Percutaneous vertebroplasty: a developing standard of care for vertebral compression fractures. AJNR Am J Neuroradiol 2001;22:373- 
81.

8. Alvarez L, Perez-Higueras A, Granizo JJ, de Miguel I, Quinones D, Rossi RE. Predictors of outcomes of percutaneous vertebroplasty for osteoporotic vertebral fractures. Spine (Phila Pa 1976) 2005;30:87-92.

9. Brown DB, Glaiberman CB, Gilula LA, Shimony JS. Correlation between preprocedural MRI findings and clinical outcomes in the treatment of chronic symptomatic vertebral compression fractures with percutaneous vertebroplasty. AJR Am J Roentgenol 2005; 184:1951-5.

10. Tanigawa N, Komemushi A, Kariya S, et al. Percutaneous vertebroplasty: relationship between vertebral body bone marrow edema pattern on MR images and initial clinical response. Radiology 2006;239:195-200.

11. Voormolen MH, van Rooij WJ, van der Graaf Y, et al. Bone marrow edema in osteoporotic vertebral compression fractures after percutaneous vertebroplasty and relation with clinical outcome. AJNR Am J Neuroradiol 2006;27:983-8.

12. Do HM. Magnetic resonance imaging in the evaluation of patients for percutaneous vertebroplasty. Top Magn Reson Imaging 2000;11:235-44.

13. Baker LL, Goodman SB, Perkash I, Lane B, Enzmann DR. Benign versus pathologic compression fractures of vertebral bodies: assessment with conventional spin-echo, chemical-shift, and STIR MR imaging. Radiology 1990;174:495-502.

14. Brown DB, Gilula LA, Sehgal M, Shimony JS. Treatment of chronic symptomatic vertebral compression fractures with percutaneous vertebroplasty. AJR Am J Roentgenol 2004;182:319-22.

15. Voormolen MH, van Rooij WJ, Sluzewski M, et al. Pain response in the first trimester after percutaneous vertebroplasty in patients with osteoporotic vertebral compression fractures with or without bone marrow edema. AJNR Am J Neuroradiol 2006;27:1579-85.

16. Dansie DM, Luetmer PH, Lane JI, Thielen KR, Wald JT, Kallmes DF. MRI findings after successful ver- tebroplasty. AJNR Am J Neuroradiol 2005;26:1595600.

17. Matin P. The appearance of bone scans following fractures, including immediate and long-term studies. J Nucl Med 1979;20:1227-31.

18. Maynard AS, Jensen ME, Schweickert PA, Marx WF, Short JG, Kallmes DF. Value of bone scan imaging in predicting pain relief from percutaneous vertebroplasty in osteoporotic vertebral fractures. AJNR Am J Neuroradiol 2000;21:1807-12.

19. Deramond H, Depriester C, Galibert P, Le Gars D. Percutaneous vertebroplasty with polymethylmethacrylate: technique, indications, and results. Radiol Clin North Am 1998;36:533-46.

20. Do HM, Kim BS, Marcellus ML, Curtis L, Marks MP. Prospective analysis of clinical outcomes after percutaneous vertebroplasty for painful osteoporotic vertebral body fractures. AJNR Am J Neuroradiol 2005;26:1623-8.

21. Hendrikse CA, Kalmijn S, Voormolen MH, Verhaar HJ, Mali WP. Percutaneous vertebroplasty in the treatment of osteoporotic vertebral compression fractures: review of the literature. Ned Tijdschr Geneeskd 2003;147:1553-9.

22. Martin JB, Jean B, Sugiu K, et al. Vertebroplasty: clinical experience and follow-up results. Bone 1999;25(2 Suppl): 11S-15S.

23. McGraw JK, Cardella J, Barr JD, et al. Society of Interventional Radiology quality improvement guidelines for percutaneous vertebroplasty. J Vasc Interv Radiol 2003;14:827-31.

24. Trout AT, Gray LA, Kallmes DF. Vertebroplasty in the inpatient population. AJNR Am J Neuroradiol 2005; 26:1629-33.

25. Zoarski GH, Snow P, Olan WJ, et al. Percutaneous vertebroplasty for osteoporotic compression fractures: quantitative prospective evaluation of longterm outcomes. J Vasc Interv Radiol 2002;13:139-48. 